\title{
Facile Preparation of Hemin-functionalized Electrochemically Reduced Graphene Oxide Nanocomposite for $\mathrm{H}_{2} \mathrm{O}_{2}$ Biosensing
}

\author{
Zhi Chen, Dong Liu, Chengxi Zhu, Libo Li, and Tianyan You ${ }^{* *}$ \\ School of Agriculture Equipment Engineering, Institute of Agricultural Engineering, Jiangsu University, \\ 301 Xuefu Road, Zhenjiang, Jiangsu 212013, China
}

(Received August 30, 2018; accepted December 27, 2018)

Keywords: Hemin, electrochemically reduced graphene oxide, nonenzymatic biosensor, hydrogen peroxide

A Hemin-functionalized electrochemically reduced graphene oxide (H-ERGO) nanocomposite was prepared for the construction of a nonenzymatic $\mathrm{H}_{2} \mathrm{O}_{2}$ biosensor. H-ERGO was directly modified on the electrode surface without using a binder by electrochemical reduction. Detailed physical and electrical characterizations of H-ERGO were conducted by scanning electron microscopy, UV-vis absorption spectroscopy, and electrochemical impedance spectroscopy (EIS). Taking advantage of the superior catalytic properties of H-ERGO, we applied the proposed biosensor to $\mathrm{H}_{2} \mathrm{O}_{2}$ analysis. Under optimized conditions, the H-ERGObased biosensor exhibited a wide linear range from 25 to 8850 and 8850 to $28850 \mu \mathrm{M}$, with a detection limit $(S / N=3)$ of $8.33 \mu \mathrm{M}$ for $\mathrm{H}_{2} \mathrm{O}_{2}$ determination. Furthermore, it was also successfully applied to detect $\mathrm{H}_{2} \mathrm{O}_{2}$ in milk samples with recoveries ranging from 94.6 to $98.1 \%$.

\section{Introduction}

Hydrogen peroxide $\left(\mathrm{H}_{2} \mathrm{O}_{2}\right)$ is closely related to many vital physiological and biochemical changes in organisms. For instance, $\mathrm{H}_{2} \mathrm{O}_{2}$ in plants is essential for stress response and the regulation of programmed cell death, while mammalian cells generate $\mathrm{H}_{2} \mathrm{O}_{2}$ to mediate diverse physiological responses, including cell proliferation, differentiation, and migration. ${ }^{(1,2)}$ In addition, $\mathrm{H}_{2} \mathrm{O}_{2}$ is of great importance in food processing, disinfection, and pharmaceutical production. Dairy industries widely use $\mathrm{H}_{2} \mathrm{O}_{2}$ as a preservative to prevent corruption and extend the shelf life of dairy products. ${ }^{(3)}$ However, the residue of $\mathrm{H}_{2} \mathrm{O}_{2}$ can cause neurodegenerative disorders, cancer, diabetes, and other health problems. ${ }^{(4)}$ Therefore, the accurate measurement of $\mathrm{H}_{2} \mathrm{O}_{2}$ level is very important. Traditional $\mathrm{H}_{2} \mathrm{O}_{2}$ determination methods include the colorimetric method, ${ }^{(5)}$ fluorescence method, ${ }^{(6)}$ flow injection method, ${ }^{(7)}$ and electro-chemiluminescence. ${ }^{(8)}$ However, the application of these methods is limited by a complicated, time-consuming, or expensive process. Moreover, these techniques require skilled operators and sophisticated instrumentation. It is generally accepted that the electrochemical method has many advantages, including fast response, cheap apparatus, simple operation, and high sensitivity and selectivity. ${ }^{(9)} \mathrm{H}_{2} \mathrm{O}_{2}$ can be reduced on ordinary electrodes; however, its

\footnotetext{
*Corresponding author: e-mail: dongliu@ujs.edu.cn

${ }^{* *}$ Corresponding author: e-mail: youty@ujs.edu.cn

https://doi.org/10.18494/SAM.2019.2124
} 
sensitivity is low and it is easily interfered by other substances. Therefore, it is necessary to develop high-performance electrochemical sensors for $\mathrm{H}_{2} \mathrm{O}_{2}$ biosensing.

Hemin is a type of ferroporphyrin derivative and the active center of various heme proteins including hemoglobin peroxidase and myoglobin. Typically, a pair of reversible or quasireversible peaks from the redox of Hemin-Fe can be obtained in cyclic voltammograms. ${ }^{(10,11)}$ Recent investigations have revealed that Hemin can exhibit peroxidase-like catalytic activity towards the $\mathrm{H}_{2} \mathrm{O}_{2}$ reduction reaction; thus, many efforts have been devoted to the fabrication of Hemin-based $\mathrm{H}_{2} \mathrm{O}_{2}$ biosensors. For instance, Lotzbeyer et al. modified the cystamine monolayer to covalently bind Hemin on gold electrodes, which exhibited high electrocatalytic activity for $\mathrm{H}_{2} \mathrm{O}_{2}$ reduction. ${ }^{(12)}$ Valentini et al. used carbon nanofibers (CNFs) to immobilize Hemin by $\pi-\pi$ interactions. The open structure of CNFs coupled with a high surface functional group density enhanced the catalytic activity of Hemin, and the fabricated biosensor achieved a low detection limit for $\mathrm{H}_{2} \mathrm{O}_{2} .{ }^{(13)}$ However, a binder, such as nafion or chitosan, is required to anchor the Hemin stably on electrodes or nanomaterials, which may complicate the fabrication procedure and limit further improvement of the analytical performance of Hemin-based biosensors.

Graphene oxide (GO), consisting of a single layer, has a large surface area and attractive mechanical properties. Abundant oxygen-containing functional groups on the surface of GO favor its surface functionalization. ${ }^{(14)}$ The reduction of GO is a significant method for the preparation of graphene, and investigations focused on reduced graphene oxide (rGO)-based sensors have received extensive attention. For example, Zhou et al. fabricated 1-aminoindole functionalized rGO on electrodes to measure phenolic substances. ${ }^{(15)}$ Chen et al. used rGO to construct a molecular adsorption gas sensor for sensing $\mathrm{NO}_{2}$ and $\mathrm{NH}_{3} .{ }^{(16)}$ Recently, the preparation of graphene by electrochemical reduction has been extensively studied. This method does not use a reducing agent, and the electrochemically reduced graphene oxide (ERGO) shows similar electrochemical performance to chemically reduced GO. ${ }^{(17)}$ For the biosensor fabrication, ERGO can be directly modified on the electrode by electrochemically reducing GO without using any binder, which can simplify the fabrication procedure.

In this work, we have prepared a Hemin-functionalized electrochemically reduced graphene oxide (H-ERGO) nanocomposite to fabricate a nonenzymatic $\mathrm{H}_{2} \mathrm{O}_{2}$ biosensor. The immobilization of Hemin and the reduction of GO were accomplished simultaneously on the electrode surface. Under optimized conditions, the proposed biosensor exhibited a wide linear range with a detection limit $(S / N=3)$ of $8.33 \mu \mathrm{M}$ for the detection of $\mathrm{H}_{2} \mathrm{O}_{2}$. It was also successfully used to detect $\mathrm{H}_{2} \mathrm{O}_{2}$ in milk samples.

\section{Materials and Methods}

\subsection{Reagents and materials}

GO was purchased from XFNANO Technology Co., Ltd. (Nanjing, China). Hemin (ferriprotoporphyrin IX chloride, $98 \mathrm{wt} \%$ ) was purchased from Sigma. All other reagents used in this work were obtained from Sinopharm Chemical Reagent Co., Ltd. (Shanghai, China). 
Milk bought from a local supermarket (Zhenjiang, China) was utilized for the real sample analysis. The ultrapure water supplied by a Milli-Q Plus system (Millipore) was used for all the solution preparations. All the experiments were conducted at room temperature.

\subsection{Instrumentation}

Scanning electron microscopy (SEM) images were taken on a S-3400N scanning electron microscope (Hitachi, Japan). UV-vis absorption and Raman spectra were obtained on a UV2450 spectrophotometer (Shimadzu, Japan) and a DXR Raman microscope (ThermoFisher, USA), respectively. Electrochemical experiments were conducted on a CHI852D electrochemical workstation (Chenhua, China). The three-electrode system was used with a modified glassy carbon electrode $(\mathrm{GCE})$ (diameter $=2 \mathrm{~mm}$ ) as the working electrode, a platinum wire electrode as the auxiliary electrode, and a $\mathrm{Ag} / \mathrm{AgCl}$ electrode (saturated $\mathrm{KCl}$ ) as the reference electrode. Electrochemical impedance spectroscopy tests were performed on a Zennium electrochemical workstation (ZAHNER, Germany).

\subsection{Preparation of Hemin-functionalized graphene oxide (H-GO)}

For the preparation of $\mathrm{H}-\mathrm{GO}, 30 \mathrm{mg}$ of $\mathrm{GO}$ and $15 \mathrm{mg}$ of Hemin were mixed in $15 \mathrm{~mL}$ of ultrapure water, followed by ultrasonication in an ultrasonic homogenizer for $30 \mathrm{~min}$. Then, the solution was stirred for $24 \mathrm{~h}$ to obtain $\mathrm{H}-\mathrm{GO}$.

\subsection{Preparation of H-ERGO}

GCE was firstly polished with $0.05 \mu \mathrm{m}$ alumina powder and sequentially sonicated in ethanol and ultrapure water, and then dried at room temperature. $2 \mu \mathrm{L}$ of $\mathrm{H}-\mathrm{GO}$ solution was cast on GCE and dried in air. Then, cyclic voltammetry (CV) was applied to reduce H-GO to $\mathrm{H}-\mathrm{ERGO} / \mathrm{GCE}$ in $0.1 \mathrm{M}$ PBS ( $\mathrm{pH} 7.0$ ) in the potential range from 0.0 to $-1.4 \mathrm{~V}$ for 50 cycles at a scan rate of $50 \mathrm{mV} \mathrm{s}^{-1}$ (18) $^{-18}$

\section{Results and Discussion}

\subsection{Principles}

To achieve the direct immobilization of Hemin without a binder during the biosensor fabrication, we developed a novel method of synthesizing H-ERGO on an electrode (Fig. 1). Briefly, Hemin was anchored on GO by $\pi-\pi$ interactions, and the obtained H-GO composite was modified on the electrode. Then, the following electrochemical reduction can reduce GO to ERGO as well as anchor the nanocomposite on the electrode. Hemin in H-ERGO retained its catalytic activity toward $\mathrm{H}_{2} \mathrm{O}_{2}$ reduction; ERGO showed a high conductivity and a large effective specific surface area. The fabricated electrochemical biosensor based on H-ERGO showed superior analytical properties toward $\mathrm{H}_{2} \mathrm{O}_{2}$. 


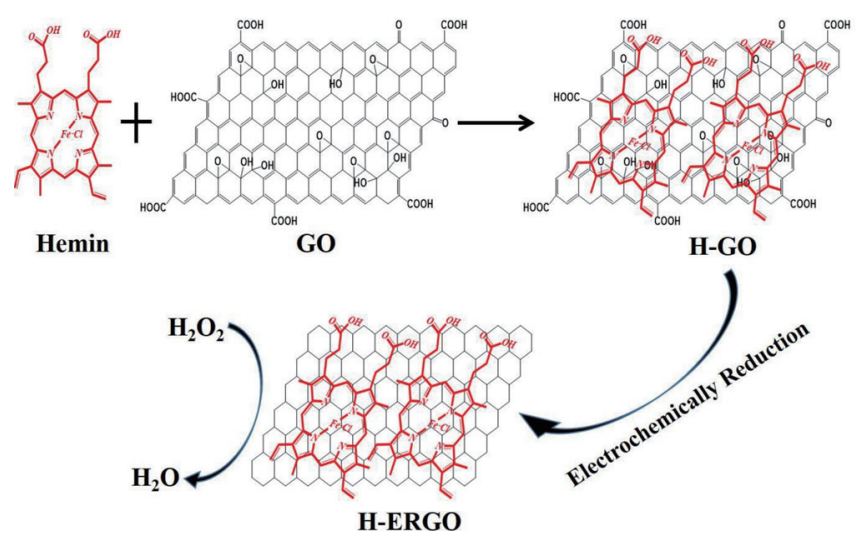

Fig. 1. (Color online) Schematic for the preparation of $\mathrm{H}-\mathrm{ERGO}$ and its application to $\mathrm{H}_{2} \mathrm{O}_{2}$ detection.

\subsection{Characterization of composite}

The functionalization of Hemin on GO was characterized by UV-vis spectroscopy. Figure 2(a) shows the UV-vis spectra of GO, Hemin, and H-GO. The peak located at $225 \mathrm{~nm}$ for GO and $\mathrm{H}-\mathrm{GO}$ was the typical characteristic absorption of GO derived from the $\pi-\pi^{*}$ transition of aromatic $\mathrm{C}=\mathrm{C}$ bonds. Typically, the $\mathrm{UV}-\mathrm{vis}$ spectra of Hemin display two characteristic absorption bands at $390 \mathrm{~nm}$ and a Q-band at 500-700 nm. ${ }^{(19)}$ For H-GO, absorption peaks were observed at 240 and $410 \mathrm{~nm}$, which were assigned to GO and Hemin, respectively. The redshifted peaks may originate from the $\pi-\pi$ interaction between GO and Hemin. ${ }^{(20)}$ Raman spectra were further obtained to characterize the crystal structures of carbon in H-GO and H-ERGO. As shown in Fig. 2(b), the results of Raman spectra show a D band at $1351 \mathrm{~cm}^{-1}$ and a $\mathrm{G}$ band at $1578 \mathrm{~cm}^{-1}$ for both H-GO and H-ERGO. Generally, the D band for carbon corresponds to the edge and disordered carbon atoms, reflecting the degree of disorder and defects, whereas the $\mathrm{G}$ band corresponds to the $\mathrm{sp}^{2}$-bond carbon atoms, reflecting the degree of symmetry and crystallization. ${ }^{(21)}$ Here, the calculated $I_{D} / I_{G}$ values are 0.86 for H-GO and 1.11 for H-ERGO [Fig. 2(b)]. The relatively larger $I_{D} / I_{G}$ value of H-ERGO demonstrated that most of the oxy-generated groups were removed and the proportion of $\mathrm{sp}^{2}$ domains was reduced after the electrochemical reduction of GO, whereas the number of defects existing in H-ERGO is higher than that in GO. ${ }^{(22)}$

The morphologies of the electrodes were characterized by SEM. In Fig. 3(a), the SEM image shows the smooth surface of the GCE. For the GO-modified GCE (GO/GCE), the clearly observed wrinkle structure indicates the successful modification of GO [Fig. 3(b)]. ${ }^{(23)}$ The aggregation of Hemin with block structures could be observed on the Hemin-modified GCE (Hemin/GCE) [Fig. 3(c)]. According to the SEM image of the H-ERGO composite modified GCE (H-ERGO/GCE), relatively small blocks of Hemin aggregation are encapsulated by the graphene on the surface of the GCE; however, no distinguishable wrinkle for typical graphene structures is observed, which may be ascribed to the functionalization of Hemin on graphene [Fig. 3(d)]. 


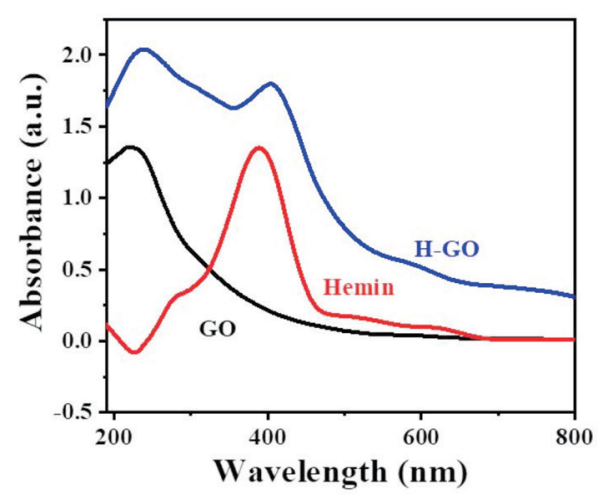

(a)

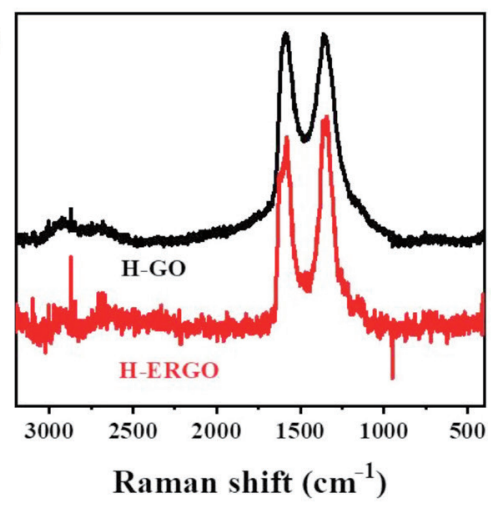

(b)

Fig. 2. (Color online) (a) UV-vis absorption spectra of GO, Hemin, and H-GO. (b) Raman spectra of GO and H-ERGO.

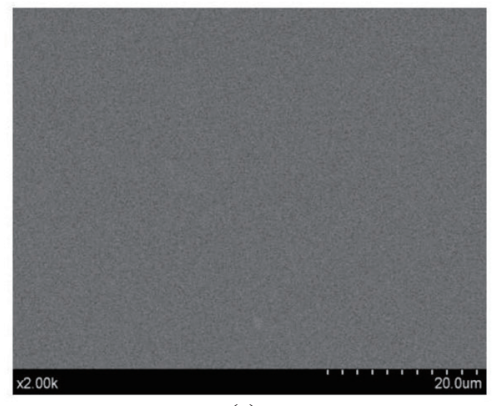

(a)

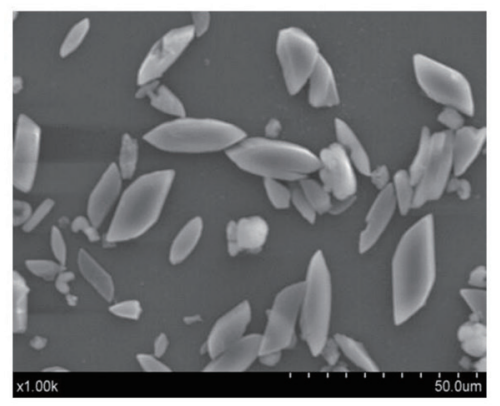

(c)

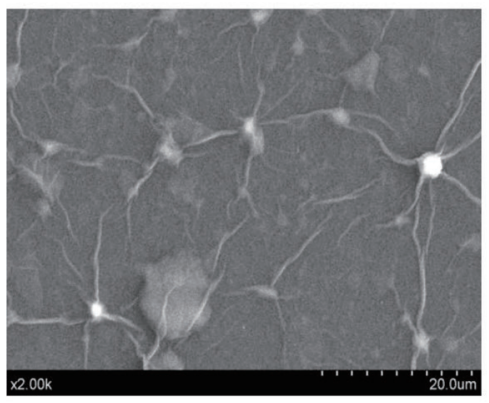

(b)

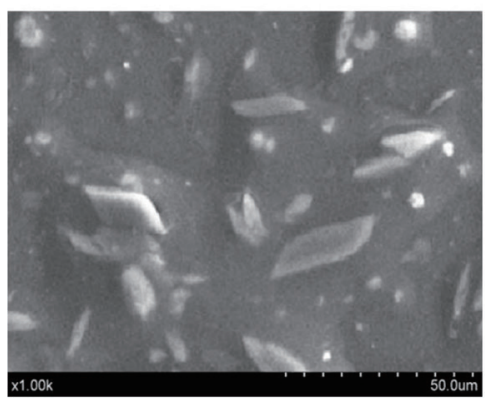

(d)

Fig. 3. SEM images of (a) GCE, (b) GO/GCE, (c) Hemin/GCE, and (d) H-ERGO/GCE.

\subsection{Electrochemical behavior of H-ERGO}

The electrochemical performance of H-ERGO was examined by $\mathrm{CV}$ and electrochemical impedance spectroscopy (EIS). Figure 4 shows the reduction of GO on $\mathrm{H}-\mathrm{GO} / \mathrm{GCE}$ and GO/ GCE. After 50 cycles, compared with that of GO/GCE, the CV curve of $\mathrm{H}-\mathrm{GO} / \mathrm{GCE}$ shows a pair of distinct redox peaks at $-0.35 \mathrm{~V}$, which is ascribed to the redox reaction of Hemin-Fe. ${ }^{(23)}$ The peak at $-1.15 \mathrm{~V}$ disappears after 50 cycles of $\mathrm{CV}$ scanning for both $\mathrm{H}-\mathrm{GO} / \mathrm{GCE}$ and $\mathrm{GO} / \mathrm{GCE}$ owing to the removal of oxy-generated groups from the GO surface. 


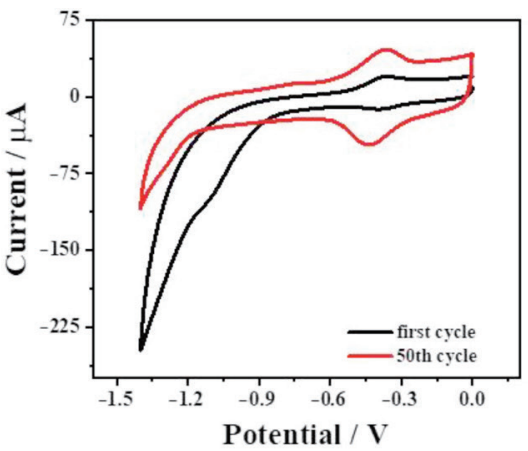

(a)

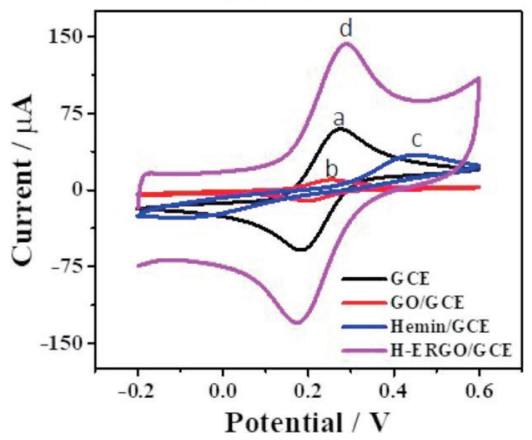

(c)

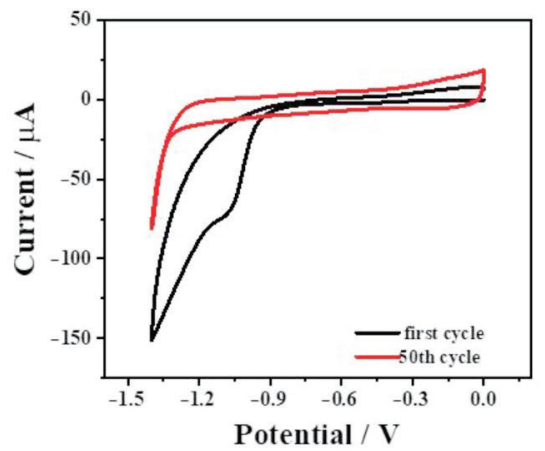

(b)

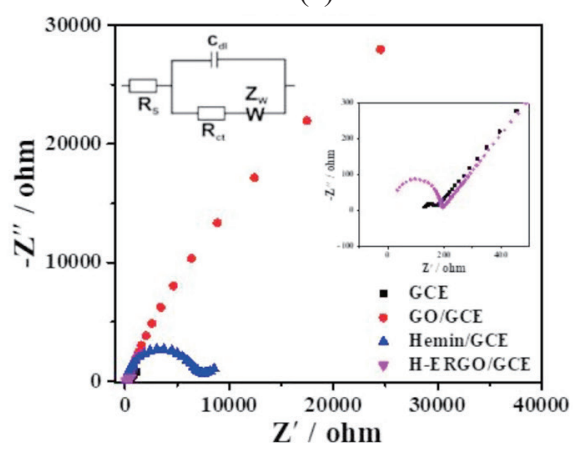

(d)

Fig. 4. (Color online) CV curves of (a) H-GO/GCE and (b) GO/GCE in $0.1 \mathrm{M}$ PBS (pH 7.0) for 50 cycles. Scan rate: $50 \mathrm{mV} \mathrm{s}^{-1}$. (c) $\mathrm{CV}$ curves of $\mathrm{GCE}, \mathrm{GO} / \mathrm{GCE}$, Hemin/GCE, and $\mathrm{H}-\mathrm{ERGO} / \mathrm{GCE}$ in $5 \mathrm{mM}\left[\mathrm{Fe}(\mathrm{CN})_{6}\right]^{3-/ 4-}$ containing $0.1 \mathrm{M} \mathrm{KCl}$. Scan rate: $100 \mathrm{mV} \mathrm{s}^{-1}$. (d) EIS spectra of GCE, GO/GCE, Hemin/GCE, and H-ERGO/GCE. Amplitude: $5 \mathrm{mV}$, frequency: 0.1 to $1 \times 10^{6} \mathrm{~Hz}$. Right inset: enlarged high-frequency region. Upper left inset: equivalent circuit $\left[R_{S}\left(C_{d l}\left(R_{c t} Z_{w}\right)\right)\right]$ fitting electrode. Rs: solution resistance, Cdl: double-layer capacitance, Rct: electron transfer resistance, $\mathrm{Zw}$ : diffusion resistance.

The CV curves of GCE, GO/GCE, Hemin/GCE, and H-ERGO/GCE are shown in Fig. 4(c). A pair of distinct redox peaks is observed on the GCE with a peak potential difference $\left(\Delta E_{p}\right)$ of $95 \mathrm{mV}$ [Fig. 4(c)]. Compared with those of GCE, the CV curves of GO/GCE and Hemin/GCE display enlarged $\Delta E_{p}$ and reduced peak currents, indicating the impeded electron transfer between the redox probe and the electrode. ${ }^{(24)}$ In contrast, the peak current of $\mathrm{H}-\mathrm{ERGO} / \mathrm{GCE}$ significantly increases with a $\Delta E_{p}$ of $115 \mathrm{mV}$ compared with that of GCE, GO/GCE, or Hemin/GCE. The electroactive area of the electrode can be estimated using the RandlesSevcik equation ${ }^{(25)}$

$$
A=\frac{I_{p}}{2.69 \times 10^{5} \times n^{3 / 2} \times D^{1 / 2} \times V^{1 / 2} \times C},
$$

where $A$ is the electroactive surface area $\left(\mathrm{cm}^{2}\right), I_{p}$ is the peak current (A), $n=1, D=1.0 \times 10^{-5}$ $\left(\mathrm{cm}^{2} \mathrm{~s}^{-1}\right), V$ is the scan rate $\left(\mathrm{V} \mathrm{s}^{-1}\right)$, and $C$ is the concentration $\left.(\mathrm{mol} \mathrm{m})^{-1}\right)$ of probe molecules. The calculated electroactive surface areas are 3.28 and $5.42 \mathrm{~mm}^{2}$ for GCE and H-ERGO/GCE, respectively. Thus, the presence of H-ERGO not only increased the electroactive area but also improved the electron transfer ability of the electrode. ${ }^{(26)}$ 
EIS was extensively used for studying the interfacial properties of the electrode. ${ }^{(27)}$ The semicircular pattern diameter of the EIS spectrum in the high-frequency region is proportional to the electron transfer resistance $\left(R_{e t}\right){ }^{(28)}$ Accordingly, the estimated $R_{e t}$ value of GCE is $45.5 \Omega$. The $R_{e t}$ values of Hemin/GCE (6623 $\Omega$ ) and GO/GCE show significant increases, revealing that both Hemin and GO block electron transfer and reduce the electron transfer rate [Fig. 4(d)]. In contrast, the calculated $R_{e t}$ value of H-ERGO/GCE is $135.5 \Omega$, indicating the good electrical property of H-ERGO.

Figure 5(a) shows the $\mathrm{CV}$ curves of $\mathrm{H}-\mathrm{ERGO} / \mathrm{GCE}$ at different scan rates ranging from 10 to $700 \mathrm{mV} \mathrm{s}^{-1}$. As the scan rate increases, both the anodic and cathodic currents increase [Fig. 5(b)]. Then, the redox peak current of H-ERGO/GCE increases linearly relative to the scan rate, and the electrochemical behavior of H-REGO is a surface control process. ${ }^{(28)}$ In addition, the effect of $\mathrm{pH}$ was studied [Fig. 5(c)]. The peak potential of H-ERGO/GCE strongly depends on the $\mathrm{pH}$ of the electrolyte. A stable set of redox peaks can be clearly observed in the $\mathrm{pH}$ range from 5.5 to 8.0, but the anode and cathode peak potentials negatively shift with increasing $\mathrm{pH}$. The formal potential $E^{\boldsymbol{\theta}}$ of the electrode is linear with pH [Fig. 5(d)]. The slope of $-55.70 \mathrm{mV}$ $\mathrm{pH}^{-1}$ is close to the theoretical value of transferring the same number of protons and electrons in a reversible redox process $\left(-58.60 \mathrm{mV} \mathrm{pH}^{-1}\right)$, indicating that this is a single-electron transfer process. ${ }^{(29)}$

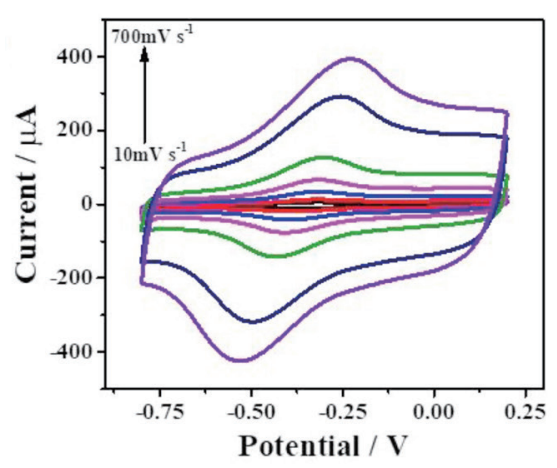

(a)

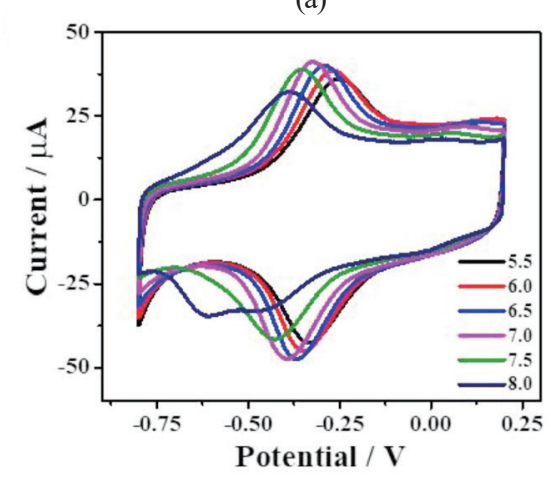

(c)

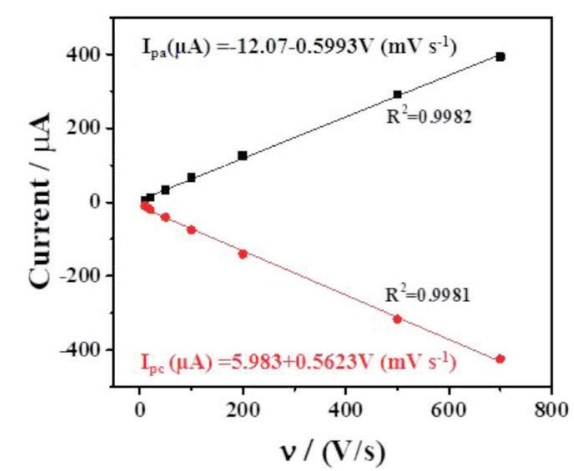

(b)

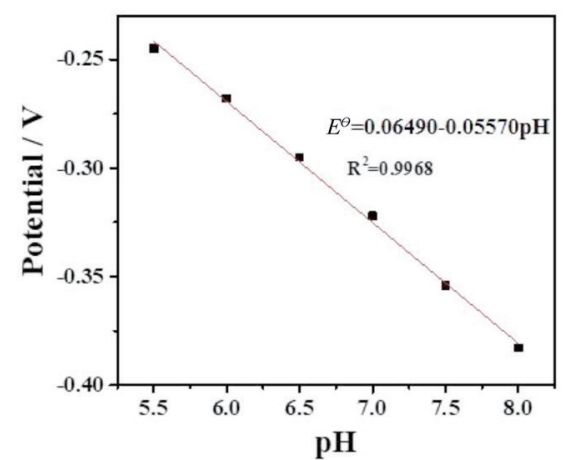

(d)

Fig. 5. (Color online) (a) CV curves of H-ERGO/GCE at different scan rates. (b) Plot of redox current of H-ERGO/ GCE against scan rate. (c) CV curves of H-ERGO/GCE in $0.1 \mathrm{M}$ PBS with different pHs of 5.5, 6.0, 6.5, 7.0, 7.5, and 8.0. (d) Effect of $\mathrm{pH}$ on the peak current. 


\subsection{Electrochemical performance of $\mathrm{H}$-ERGO for $\mathrm{H}_{2} \mathrm{O}_{2}$ detection}

Figure 6 shows the responses of GCE, ERGO/GCE, Hemin/GCE, and H-ERGO/GCE to $\mathrm{H}_{2} \mathrm{O}_{2}$. As shown in Fig. 6(a), a relatively poor electrochemical response of GCE to $\mathrm{H}_{2} \mathrm{O}_{2}$ is observed. Compared with GCE, ERGO/GCE shows an improved response with a large charging current, owing to the excellent conductivity as well as large surface area of ERGO [Fig. 6(b)]. For Hemin/GCE, the current response to $\mathrm{H}_{2} \mathrm{O}_{2}$ is significantly enhanced owing to the catalytic property of $\mathrm{Fe}^{3+}$ in Hemin [Fig. 6(c)]. According to previous reports, the simplified mechanism of $\mathrm{H}_{2} \mathrm{O}_{2}$ reduction by $\mathrm{H}-\mathrm{REGO}$ can be expressed as the following scheme: ${ }^{(30)}$

Hemin $\left(\mathrm{Fe}^{3+}\right)+\mathrm{H}_{2} \mathrm{O}_{2} \rightarrow$ Compound $\mathrm{I}\left(\mathrm{Fe}^{4+}=\mathrm{O}\right)+\mathrm{H}_{2} \mathrm{O}$,

Compound I $\left(\mathrm{Fe}^{4+}=\mathrm{O}\right)+\mathrm{H}^{+}+\mathrm{e}^{-} \rightarrow$ Compound II,

Compound II $+\mathrm{H}^{+}+\mathrm{e}^{-} \rightarrow \mathrm{Hemin}\left(\mathrm{Fe}^{3+}\right)+\mathrm{H}_{2} \mathrm{O}$.

However, the inert surface of GCE limits the activity of the mimetic enzyme Hemin. The superior electrochemical performance of $\mathrm{H}-\mathrm{ERGO} / \mathrm{GCE}$ was demonstrated by the previous tests. Upon the addition of $\mathrm{H}_{2} \mathrm{O}_{2}$, the $\mathrm{H}-\mathrm{ERGO} / \mathrm{GCE}$ response significantly increases and it displays superior catalytic activity [Fig. 6(d)].

Figure 7 shows the electrochemical responses of GCE, ERGO/GCE, Hemin/GCE, and $\mathrm{H}$-ERGO/GCE to $10 \mathrm{mM} \mathrm{H}_{2} \mathrm{O}_{2}$. Clearly, H-ERGO/GCE exhibits the largest response current, indicating that $\mathrm{H}-\mathrm{ERGO}$ shows the highest catalytic activity for $\mathrm{H}_{2} \mathrm{O}_{2}$ reduction.

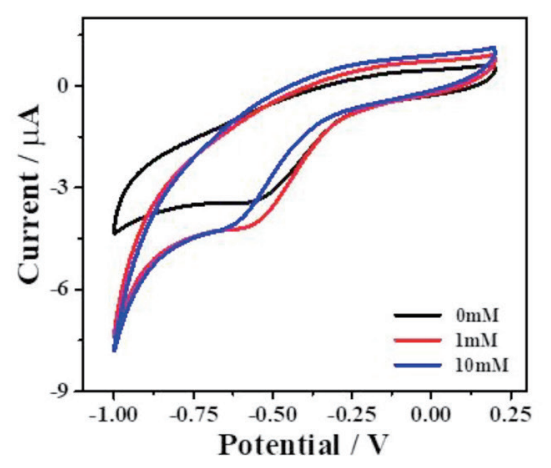

(a)

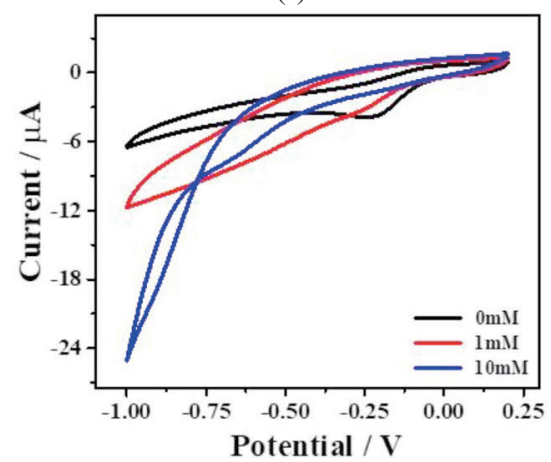

(c)

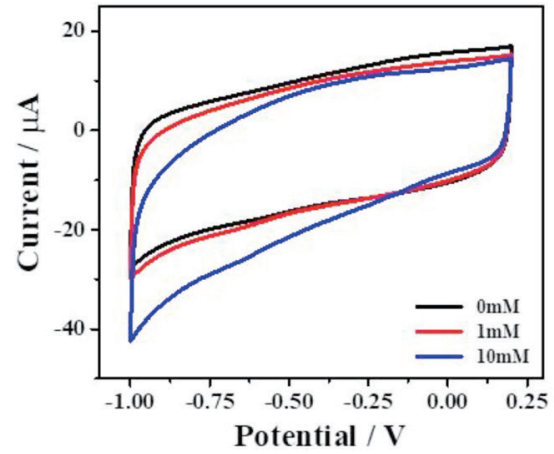

(b)

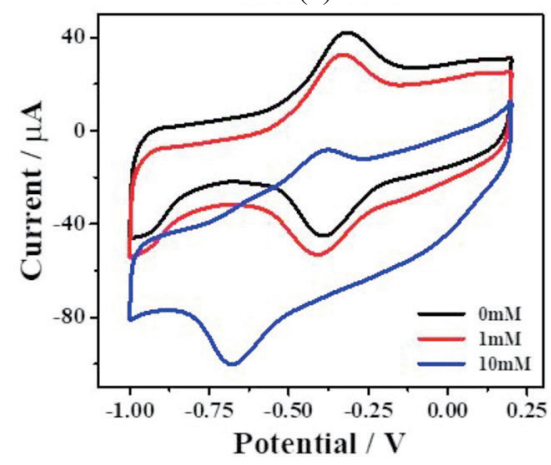

(d)

Fig. 6. (Color online) $\mathrm{CV}$ curves of (a) GCE, (b) ERGO/GCE, (c) Hemin/GCE, and (d) H-ERGO/GCE in $0.1 \mathrm{M}$ PBS ( $\mathrm{pH}$ 7.0) containing different $\mathrm{H}_{2} \mathrm{O}_{2}$ concentrations. 


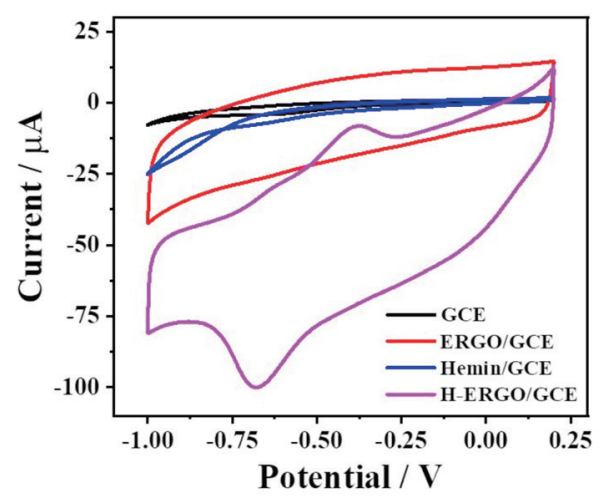

Fig. 7. (Color online) CV curves of GCE, ERGO/GCE, Hemin/GCE, and H-ERGO/GCE in 0.1 M PBS (pH 7.0) containing $10 \mathrm{mM} \mathrm{H}_{2} \mathrm{O}_{2}$.

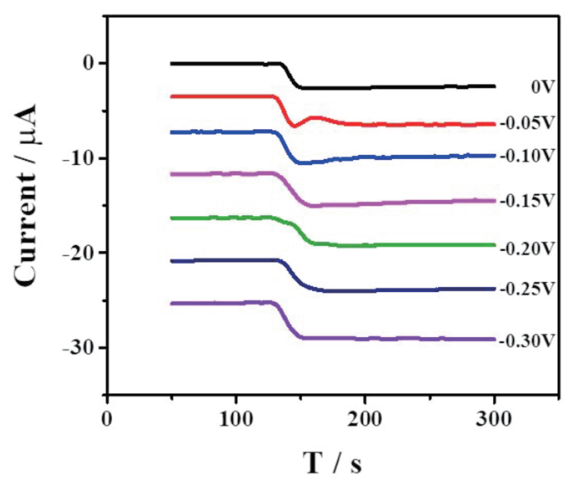

(a)

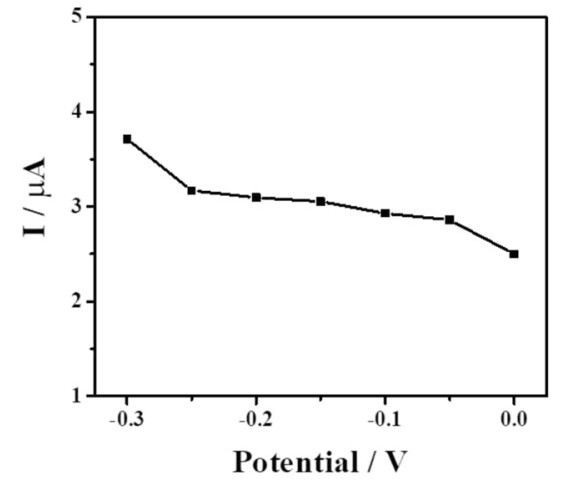

(b)

Fig. 8. (Color online) (a) Current responses of $\mathrm{H}-\mathrm{ERGO} / \mathrm{GCE}$ toward $1 \mathrm{mM} \mathrm{H}_{2} \mathrm{O}_{2}$ at different potentials. (b) Effect of applied potential on current.

The current responses of H-ERGO/GCE toward $1 \mathrm{mM} \mathrm{H}_{2} \mathrm{O}_{2}$ at different potentials were tested [Fig. 8(a)]. With the decrease in potential from 0 to $-0.30 \mathrm{~V}$, the current gradually increases [Fig. 8(b)]. However, at a low potential, common substances, such as urea and ascorbic acid (AA), may affect the determination of $\mathrm{H}_{2} \mathrm{O}_{2}$. Therefore, $-0.15 \mathrm{~V}$ was selected as a suitable potential for $\mathrm{H}_{2} \mathrm{O}_{2}$ detection.

Figure 9(a) shows the response of $\mathrm{H}-\mathrm{ERGO} / \mathrm{GCE}$ to $\mathrm{H}_{2} \mathrm{O}_{2}$ in a current-time (i-t) plot at the potential of $-0.15 \mathrm{~V}$. Upon the addition of $\mathrm{H}_{2} \mathrm{O}_{2}$, the current increases and reaches a stable value rapidly. As shown in Fig. 9(b), the linear range for $\mathrm{H}_{2} \mathrm{O}_{2}$ detection at $\mathrm{H}-\mathrm{ERGO} / \mathrm{GCE}$ is 25 to $8850 \mu \mathrm{M}$, with the linear regression equation $I(\mu \mathrm{A})=0.03982+6.609 \mathrm{C}(\mathrm{mM})\left(R^{2}=0.9884\right)$; when the $\mathrm{H}_{2} \mathrm{O}_{2}$ concentration ranges from 8850 to $28850 \mu \mathrm{M}$, the linear regression equation is $I(\mu \mathrm{A})=29.59+2.982 \mathrm{C}(\mathrm{mM})\left(R^{2}=0.9912\right)$. When the $\mathrm{C}_{\mathrm{H} 2 \mathrm{O} 2}$ values are below $8850 \mu \mathrm{M}$, $\mathrm{H}_{2} \mathrm{O}_{2}$ with relatively low concentrations can be reduced quickly at $\mathrm{H}-\mathrm{ERGO} / \mathrm{GCE}$, producing fast response signals as shown in Fig. 9(a). Thus, a high sensitivity was obtained at H-ERGO/ $\mathrm{GCE}$ for $\mathrm{H}_{2} \mathrm{O}_{2}$ in the range from 25 to $8850 \mu \mathrm{M}$. However, for $\mathrm{C}_{\mathrm{H} 2 \mathrm{O} 2}$ ranging from 8850 to $28850 \mu \mathrm{M}$, a relatively low sensitivity was obtained. ${ }^{(31)}$ The detection limit is $8.33 \mu \mathrm{M}(S / N=3)$. 


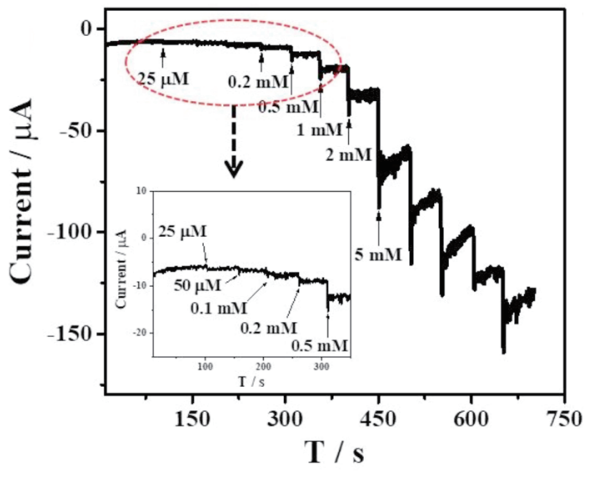

(a)

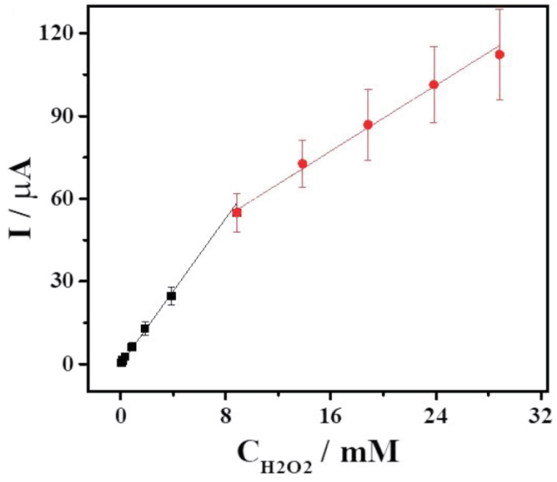

(b)

Fig. 9. (Color online) (a) Amperometric response curve of $\mathrm{H}-\mathrm{ERGO} / \mathrm{GCE}$ to successive injection of $\mathrm{H}_{2} \mathrm{O}_{2}$ into 0.1 M PBS (pH 7.0). (b) Calibration curve of the reduction currents at $\mathrm{H}-\mathrm{ERGO} / \mathrm{GCE}$ against $\mathrm{H}_{2} \mathrm{O}_{2}$ concentration.

Table 1

Comparison of analytic performance of different electrochemical biosensors for $\mathrm{H}_{2} \mathrm{O}_{2}$ detection.

\begin{tabular}{lccc}
\hline Electrode & $\begin{array}{c}\text { Linear range } \\
(\mu \mathrm{M})\end{array}$ & $\begin{array}{c}\text { Detection limit } \\
(\mu \mathrm{M})\end{array}$ & Reference \\
\hline Au/HRP/GS/CS/GCE & $5-5130$ & 1.7 & 32 \\
HRP/PTMSPA@GNRs & $10-1000$ & 0.06 & 33 \\
HRP/silica matrix & $20-200$ & 3 & 34 \\
Nafion/HRP/GNSs-TiO2 & $41-630$ & 5.9 & 35 \\
ND-NS(HRP)/ME & $1000-45000$ & 59 & 36 \\
H-ERGO/GCE & $25-8850 ;$ & 8.33 & This work \\
\hline
\end{tabular}

The fabricated H-ERGO/GCE shows a lower detection limit with a wider linear range than the previously reported $\mathrm{H}_{2} \mathrm{O}_{2}$ analytical methods (Table 1).

\subsection{Selectivity, reproducibility, and stability of the $\mathrm{H}_{2} \mathrm{O}_{2}$ biosensor}

To examine the applicability of the proposed biosensor in real samples, the interferences of several substances, including glucose (glu), ascorbic acid (AA), and urea, were investigated. Figure 10(a) shows the $I-t$ responses upon the consecutive injection of $\mathrm{H}_{2} \mathrm{O}_{2}(0.2 \mathrm{mM})$, urea (1.0 mM), glu (1.0 mM), AA $(1.0 \mathrm{mM})$, and $\mathrm{H}_{2} \mathrm{O}_{2}(0.2 \mathrm{mM})$. Clearly, these interferences show the insignificant effect of the biosensor on $\mathrm{H}_{2} \mathrm{O}_{2}$ detection, revealing the high selectivity of the proposed sensor.

Four intermittent measurements were performed to detect $0.2 \mathrm{mM} \mathrm{H}_{2} \mathrm{O}_{2}$, and the obtained relative standard deviation (RSD) was 2.5\% [Fig. 10(b)]. The reproducibility of the biosensors was estimated by testing the response of five different electrodes towards $1 \mathrm{mM} \mathrm{H}_{2} \mathrm{O}_{2}$. The result indicates a satisfactory reproducibility of biosensors with an RSD of 3.7\%. Moreover, the stability of the sensor was tested. The response maintained $87 \%$ of the initial value, after storage at $4{ }^{\circ} \mathrm{C}$ for one week. The good stability may result from the enzymatic mimetic properties of H-ERGO and the elimination of enzymatic denaturation problems. 


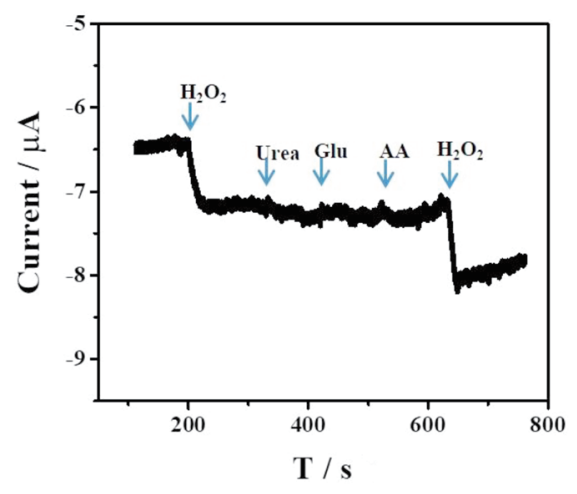

(a)

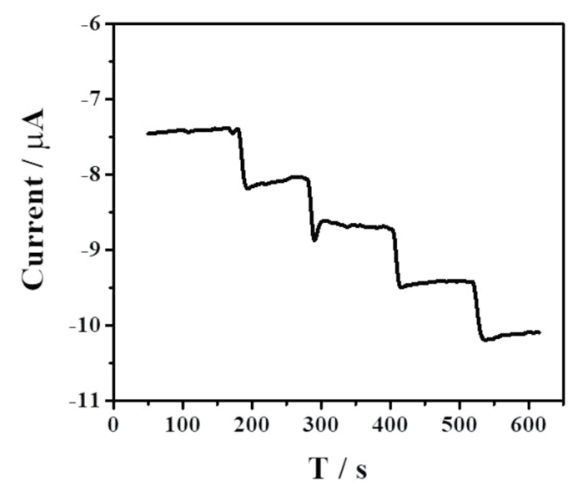

(b)

Fig. 10. (Color online) (a) $I-t$ curve of $\mathrm{H}-\mathrm{ERGO} / \mathrm{GCE}$ upon successive addition of urea, glu, AA, and $\mathrm{H}_{2} \mathrm{O}_{2}$. (b) $I-t$ curve of $\mathrm{H}-\mathrm{ERGO} / \mathrm{GCE}$ upon successive addition of $\mathrm{H}_{2} \mathrm{O}_{2}$.

Table 2

Recoveries of $\mathrm{H}_{2} \mathrm{O}_{2}$ in real samples $(n=3)$.

\begin{tabular}{lcccc}
\hline Samples & Added $(\mu \mathrm{M})$ & Detected $(\mu \mathrm{M})$ & Recovery $(\%)$ & RSD $(\%)$ \\
\hline I & 30 & 29.1 & 97.2 & 6.5 \\
II & 50 & 47.3 & 94.6 & 2.8 \\
III & 100 & 98.1 & 98.1 & 3.7 \\
\hline
\end{tabular}

\subsection{Real sample analysis}

To prove its applicability, the biosensor was applied to analyze milk samples by the standard addition method. $^{(37)}$ The test results are summarized in Table 2 . The calculated recoveries for milk samples are between 94.6 and $98.1 \%$ with RSDs below $6.5 \%$.

\section{Conclusions}

We have fabricated a high-performance nonenzymatic $\mathrm{H}_{2} \mathrm{O}_{2}$ biosensor based on H-ERGO. In contrast to typical methods, the biosensor here was fabricated by the electrochemical reduction method without using a binder. A high catalytic performance toward $\mathrm{H}_{2} \mathrm{O}_{2}$ reduction was achieved by coupling Hemin with graphene. The proposed biosensor displayed good sensitivity and selectivity with high stability toward $\mathrm{H}_{2} \mathrm{O}_{2}$ detection. Furthermore, our biosensor was successfully employed to detect $\mathrm{H}_{2} \mathrm{O}_{2}$ in milk samples. The development of this type of sensor has a good prospect in the application to detection and provides a reference for more rapid detection.

\section{Acknowledgments}

We wish to thank the Natural Science Foundation of Jiangsu Province (No. BK20160490), National Natural Science Foundation of China (Nos. 21475124 and 21675065), Innovation 
and Entrepreneurship Training Programs for Undergraduates (201710299095X), and Priority Academic Program Development of Jiangsu Higher Education Institutions.

\section{References}

1 M. Dynowski, G. Schaaf, D. Loque, O. Moran, and U. Luddewig: Biochem. J. 414 (2008) 53. https://doi. org/10.1042/BJ20080287

2 S. G. Rhee: Science 312 (2006) 1882. https://doi.org/10.1126/science.1130481

3 B. K. Saha, M. Y. Ali, M. Chakraborty, Z. Islam, and A. K. Hira: Pakistan J. Nutrit. 2 (2003) 36.

4 M. Valko, D. Leibfritz, J. Moncola, M. T. D. Cronin, M. Mazura, and J. Telser: Int. J. Biochem. Cell Biol. 39 (2007) 44. https://doi.org/10.1016/j.biocel.2006.07.001

5 J. Pla-Tolos, Y. Moliner-Martinez, C. Molins-Legua, and P. Campins-Falco: Sens. Actuators, B 231 (2016) 837. https://doi.org/10.1016/j.snb.2016.03.094

6 L. L. Liang, F. F. Lan, L. Li, M. Su, S. G. Ge, J. H. Yu, H. Y. Liu, and M. Yan: Biosens. Bioelectron. 82 (2016) 204. https://doi.org/10.1016/j.bios.2016.03.076

7 P. Reanpang, S. Themsirimongkon, S. Saipanya, O. Chailapakul, and J. Jakmunee: Talanta 144 (2015) 868. https://doi.org/10.1016/j.talanta.2015.07.041

8 C. Z. Wang, Y. F. E, L. Z. Fan, Z. H. Wang, H. B. Liu, Y. L. Li, S. H. Yang, and Y. L. Li: Adv. Mater. 19 (2007) 3677. https://doi.org/10.1002/adma.200701386

9 K. R. Rogers, J. Y. Becker, J. Wang, and F. Lu: Field Anal. Chem. Technol. 3 (1999) 161. https://doi. org/10.1002/(SICI)1520-6521(1999)3:3<161::AID-FACT3>3.0.CO;2-X

10 G. F. Zhang and P. K. Dasgupta: Anal. Chem. 64 (1992) 517. https://doi.org/10.1021/ac00029a013

11 C. J. Gu, F. Y. Kong, Z. D. Chen, D. H. Fan, H. L. Fang, and W. Wang: Biosens. Bioelectron. 78 (2016) 300. https://doi.org/10.1016/j.bios.2015.11.035

12 T. Lotzbeyer, W. Shuhmann, and H. L. Schmidt: J. Electroanal. Chem. 395 (1995) 341. https://doi. org/10.1016/0022-0728(95)04265-P

13 F. Valentini, L. Cristofanelli, M. Carbone, and G. Palleschi: Electrochim. Acta 63 (2012) 37. https://doi. org/10.1016/j.electacta.2011.12.027

14 S. H. Lee, D. R. Dreyer, J. H. An, A. Velamakanni, R. D. Piner, S. J. Park, Y. W. Zhu, S. O. Kim, C. W. Bielawski, and R. S. Ruoff: Macromol. Rapid Commun. 31 (2010) 281. https://doi.org/10.1002/marc.200900641

15 X. H. Zhou, L. H. Liu, X. Bai, and H. C. Shi: Sens. Actuators, B 181 (2013) 661. https://doi.org/10.1016/ j.snb.2013.02.021

16 G. H. Lu, L. E Ocola, and J. H. Chen: Nanotechnology 20 (2009) 445502. https://doi.org/10.1088/0957$4484 / 20 / 44 / 445502$

17 H. L. Guo, X. F. Wang, Q. Y. Qian, F. B. Wang, and X. H. Xia: ACS Nano 3 (2009) 2653. https://doi. org/10.1021/nn900227d

18 L. Yang, D. Liu, J. S. Huang, and T. Y. You: Sens. Actuators, B 193 (2014) 166. https://doi.org/10.1016/ j.snb.2013.11.104

19 W. Lei, L. H. Wu, W. J. Huang, Q. L. Hao, Y. H. Zhang, and X. F. Xia: J. Mater. Chem. B 2 (2014) 4324. https://doi.org/10.1039/c4tb00313f

20 H. L. Zou, B. L. Li, H. Q. Luo, and N. B. Li: Sens. Actuators, B 207 (2015) 535. https://doi.org/10.1016/ j.snb.2014.10.121

21 S. Stankovich, D. A. Dikin, R. D. Piner, K. A. Kohlhaas, A. Kleinhammes, Y. Y. Jia, Y. Wu, S. T. Nguyen, and R. S. Ruoff: Carbon 45 (2007) 1558. https://doi.org/10.1016/j.carbon.2007.02.034

22 F. P. Liu, J. Q. Tang, J. Xu, Y. Shu, Q. Xu, H. M. Wang, and X. Y. Hu: Biosens. Bioelectron. 86 (2016) 871. https://doi.org/10.1016/j.bios.2016.07.089

23 M. A. Raj and S. A. John: J. Phys. Chem. C 117 (2013) 4326. https://doi.org/10.1021/jp400066z

24 M. H. Zhang, R. Yuan, Y. Q. Chai, S. H. Chen, X. Zhong, H. A. Zhong, and C. Wang: RSC Adv. 2 (2012) 4639. https://doi.org/10.1039/C2RA20374J

25 M. Pacios, M. del Valle, J. Bartroli, and M. J. Esplandiu: J. Electroanal. Chem. 619 (2008) 117. https://doi. org/10.1016/j.jelechem.2008.03.019

26 W. Zhang, G. M. Xie, S. F. Li, L. S. Lu, and B. Liu: Appl. Surf. Sci. 258 (2012) 8222. https://doi.org/10.1016/ j.apsusc.2012.05.025

27 X. Y. Lin, Y. N. Ni, and S. Kokot: J. Hazard. Mater. 243 (2012) 232. https://doi.org/10.1016/j.jhazmat.2012.10.026

28 H. Y. Song, Y. N. Ni, and S. Kokot: Anal. Chim. Acta 788 (2013) 24. https://doi.org/10.1016/j.aca.2013.06.016 
29 A. P. Periasamy, Y. J. Chang, and S. M. Chen: Bioelectrochemistry 80 (2011) 114. https://doi.org/10.1016/ j.bioelechem.2010.06.009

30 Y. Zhang, Z. Xia, H. Liu, M. J. Yang, L. L. Lin, and Q. Z. Li: Sens. Actuators, B 188 (2013) 496. https://doi. org/10.1016/j.snb.2013.07.010

31 X. X. Dong, M. Y. Li, N. N. Feng, Y. M. Sun, C. Yang, and Z. L. Xu: RSC Adv. 5 (2015) 86485. https://doi. org/10.1039/C5RA18560B

32 K. F. Zhou, Y. H. Zhu, X. L. Yang, J. Luo, C. Z. Li, and S. R. Luan: Electrochim. Acta 55 (2010) 3055. https:// doi.org/10.1016/j.electacta.2010.01.035

33 S. Komathi, A. I. Gopalan, S. K. Kim, G. S. Anand, and K. P. Lee: Electrochim. Acta 92 (2013) 71. https://doi. org/10.1016/j.electacta.2013.01.032

34 S. Yang, W. Z. Jia, Q. Y. Qian, Y. G. Zhou, and X. H. Xia: Anal. Chem. 81 (2009) 3478. https://doi.org/10.1021/ ac802739h

35 Y. Wang, X. L. Ma, Y. Wen, Y. Y. Xing, Z. R. Zhang, and H. F. Yang: Biosens. Bioelectron. 25 (2010) 2442. https://doi.org/10.1016/j.bios.2010.04.002

36 A. I. Gopalan, S. Komathi, G. S. Anand, and K. P. Lee: Biosens. Bioelectron. 46 (2013) 136. https://doi. org/10.1016/j.bios.2013.02.036

37 E. Akyilmaz, G. Oyman, E. Cinar, and G. Odabas: Prep. Biochem. Biotechnol. 47 (2017) 86. https://doi.org/10. $1080 / 10826068.2016 .1172235$ 